\title{
ELABORAÇÃO DE BISCOITO INTEGRAL UTILIZANDO ÓLEO E FARINHA DA POLPA DE ABACATE
}

\author{
MARCIA ALVES CHAVES* \\ CARLA ROSANE BARBOZA MENDONÇA** \\ CAROLINE DELLINGHAUSEN BORGES $* * *$ \\ ORNELLA MARIA PORCU****
}

\begin{abstract}
O objetivo deste trabalho foi preparar biscoitos integrais com farinha e óleo da polpa de abacate e avaliar os produtos quanto às suas características físico-químicas e sensoriais. A polpa de abacates da variedade Margarida foi desidratada, prensada a frio para extração do óleo e triturada para produção da farinha. Nas cinco formulações de biscoitos elaboradas, exceto a padrão, substitui-se parcialmente a farinha integral e a manteiga por farinha de polpa de abacate e óleo de abacate em diferentes proporções. A polpa de abacate Margarida apresentou, de modo geral, características similares às descritas na literatura e a farinha obtida da polpa dos abacates mostrou características semelhantes às farinhas de trigo convencional e integral. Os biscoitos elaborados com farinha e óleo de abacate apresentaram maiores teores de acidez e umidade que a formulação padrão e as formulações com maiores conteúdos de farinha de abacate evidenciaram maior concentração de minerais e fibras. A análise sensorial demonstrou boa aceitação dos biscoitos, no entanto as formulações com menores proporções de farinha e óleo de abacate apresentaram melhores características sensoriais.
\end{abstract}

* Discente do Curso de Pós-Graduação (Especialização) em Ciência dos Alimentos, Centro de Ciências Químicas, Farmacêuticas e de Alimentos, Ciência dos Alimentos, Universidade Federal de Pelotas (UFPel), Pelotas, RS, Brasil (e-mail: marcia_alves_chaves@hotmail.com).

** Doutora em Química, Centro de Ciências Químicas, Farmacêuticas e de Alimentos, UFPel, Pelotas, RS, Brasil (e-mail: carlaufpel@hotmail.com).

*** Doutora em Biotecnologia Agrícola, Centro de Ciências Químicas, Farmacêuticas e de Alimentos, UFPel, Pelotas, RS, Brasil (e-mail: caroldellin@hotmail.com).

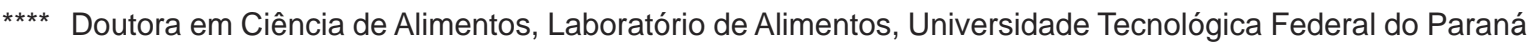
(UTFPR), Medianeira, PR, Brasil (e-mail: ornella@uftpr.edu.br). 


\section{INTRODUÇÃo}

O abacate (Persea americana), fruto tropical e subtropical, é originário da América Central, mais especificamente da Guatemala, Antilhas e México. A polpa desse fruto representa $70 \%$ de sua massa total e contém elevados teores de lipídios. O abacate apresenta em média $6,94 \mathrm{~g}$ de carboidratos; 17,34 $\mathrm{g}$ de lipídeos; $2,08 \mathrm{~g}$ de proteínas; 2,72 $\mathrm{g}$ de fibras e 70,92 $\mathrm{g}$ de água em 100 gramas de polpa in natura (ROCHA, 2008; DAIUTO et al., 2010). Esse fruto tem sido reconhecido por seus benefícios à saúde, especialmente em função dos compostos presentes na fração lipídica, como ácidos graxos ômega, fitoesterois, tocoferois e esqualeno (DING, 2007; DOS SANTOS et al., 2012; BERASATEGI et al., 2012).

Pesquisa realizada no México divulgou que 45 voluntários que ingeriram abacate diariamente, durante uma semana, apresentaram queda média de $17 \%$ na taxa de colesterol do sangue. Esses indícios podem estar associados à composição de ácidos graxos ômega 9 (n-9) presente nesse fruto, os quais parecem apresentar efeitos benéficos para a saúde do consumidor em relação à prevenção de doenças cardiovasculares, em particular na substituição de alimentos que contenham gorduras de origem animal (TANGO, CARVALHO e SOARES, 2004; BORGES e MELO, 2011).

O abacate destaca-se sob o ponto de vista nutricional devido ao elevado valor calórico que apresenta, bastante superior à maioria das frutas. Tal fato se deve ao alto teor de matéria graxa desse fruto, rica em ácidos graxos monoinsaturados, especialmente o oleico, e o baixo conteúdo de ácidos graxos saturados. Essa característica, somada a sua riqueza em vitaminas E, C, B6, $\beta$-caroteno e potássio o tornam interessante para o consumo direto na dieta humana (OZDEMIR e TOPUZ, 2004).

Segundo Tango, Carvalho e Soares (2004), o óleo do abacate pode ser utilizado para fins alimentícios, tendo porém como obstáculo para obtenção do conteúdo lipídico o alto teor de umidade, que afeta o rendimento da extração. Para aumentar esse rendimento torna-se necessária a secagem do material, o que pode elevar o custo do processo. Esse óleo tem sido muito usado em cosméticos e sua matéria insaponificável explorada em aplicações farmacêuticas com fins terapêuticos, dermatológicos ou medicinais (MOSTERT et al., 2007; DING, 2007).

O resíduo da polpa, oriundo do processo de extração, gera acúmulo de material fibroso nas indústrias de beneficiamento, elevando os custos para sua remoção. Entretanto, o alto teor de fibras desse subproduto permite que a farinha resultante da extração do óleo possa ser utilizada na elaboração de produtos de panificação (biscoitos e pães) e massas alimentícias. Nesse sentido, o desenvolvimento de produtos à base de abacate, além de representar novas opções ao consumo dessa fruta, pode propiciar alternativas alimentares associadas aos benefícios das fibras ao organismo (CANCIAM, SANTOS e OLEGARIO, 2008).

O objetivo deste trabalho foi elaborar biscoitos integrais utilizando a farinha da polpa de abacate Margarida, oriunda do processo de extração lipídica e o óleo dessa fruta a fim de produzir alimento com alto valor nutricional e características benéficas ao organismo. Mais especificamente, pretendeu-se extrair o óleo da polpa desidratada; elaborar farinha a partir do resíduo originado; preparar diferentes formulações de biscoitos; avaliar as características físico-químicas da polpa, da farinha, do óleo obtido e dos produtos elaborados a partir do abacate, bem como identificar as características sensoriais dos biscoitos produzidos e sua aceitação pelos consumidores.

\section{MATERIAL E MÉTODOS}

\subsection{MATERIAL}

Obteve-se abacate da variedade Margarida em estádio de maturação incompleto, sendo a matéria-prima mantida sob armazenamento à temperatura ambiente $\left(28^{\circ} \mathrm{C} \pm 1^{\circ} \mathrm{C}\right)$ até alcançar $\mathrm{O}$ 
ponto ideal de maturação ( 7 e 8 Brix), avaliado pelo teor de sólidos solúveis da polpa e pela textura do fruto.

A escolha do abacate da variedade Margarida fundamentou-se em sua disponibilidade no mercado brasileiro, sendo essa variedade produzida na entressafra entre os meses de julho e novembro (OLIVEIRA et al., 2013), culminando com o período de execução deste experimento. Ainda, pesquisas prévias conduzidas por Salgado et al. (2008) indicam que essa variedade apresenta elevado percentual em polpa, constituindo excelente matéria-prima para a extração do óleo.

Os ingredientes utilizados no desenvolvimento das formulações de biscoito (farinha de trigo integral, farinha de aveia, manteiga, açúcar mascavo, ovos, fermento em pó, sal e raspas de laranja) foram adquiridos em supermercado da cidade de Medianeira (PR) e conduzidos aos laboratórios do Bloco de Tecnologia em Alimentos da Universidade Tecnológica Federal do Paraná, campus Medianeira. A Tabela 1 apresenta os ingredientes utilizados na elaboração da formulação padrão com os respectivos percentuais empregados para o preparo dos biscoitos integrais.

TABELA 1 - FORMULAÇÃO PADRÃO DOS BISCOITOS INTEGRAIS

\begin{tabular}{cc}
\hline INGREDIENTES & $\%$ \\
\hline Farinha de Trigo Integral & 45,49 \\
Farinha de Aveia & 5,05 \\
Manteiga & 22,97 \\
Açúcar Mascavo & 18,38 \\
Ovos & 6,89 \\
Fermento em pó & 0,69 \\
Sal & 0,29 \\
Raspas de Laranja & 0,23
\end{tabular}

Para a extração dos lipídios, pelo método de Soxhlet, empregou-se éter de petróleo 99 \% (Synth, São Paulo, Brasil) e para as determinações físico-químicas reagentes de grau analítico. Durante o preparo da polpa de abacate para secagem utilizou-se ácido cítrico (Vetec, Rio de Janeiro, Brasil) como antioxidante.

\subsection{INSTRUMENTAÇÃO}

Para os experimentos e análises foram utilizados os seguintes equipamentos: estufa de circulação de ar (Quimis, modelo Digi Mec), forno mufla (Forlab), prensa mecânica com capacidade para $1 \mathrm{~kg}$ de amostra (Marconi), refratômetro de Abbé (Atago, marca n-1), medidor de atividade água (AquaLab ${ }^{\circledR}$, modelo 4TE, 4TEV, DUO); bloco digestor de nitrogênio (Marconi, modelo MA851), destilador de proteínas (Tecnal, modeloTE-03611) e moinho de facas (Solab, modelo SL31).

\subsection{PREPARO DA AMOSTRA}

Os abacates da variedade Margarida foram selecionados quanto a avarias, lavados em água clorada contendo $100 \mathrm{mg} \cdot \mathrm{L}^{-1}$ de cloro ativo durante 15 minutos e enxaguados em água corrente. Seguiram-se as etapas de pesagem, corte, despolpamento e nova pesagem.

A polpa de abacate, submergida em solução de ácido cítrico a $1 \%$ durante 15 minutos, foi triturada e conduzida à secagem em estufa com circulação de ar. 


\subsection{PESO PERCENTUAL DO ABACATE IN NATURA}

Realizou-se a pesagem de 30 frutos inteiros, da polpa e dos caroços obtidos e efetuou-se o cálculo do peso médio da fruta inteira e de suas partes em separado, expressando os resultados em percentual de acordo com Salgado et al. (2008).

\subsection{EXTRAÇÃO DO ÓLEO DA POLPA DE ABACATE}

Para extração do óleo de abacate, a polpa foi submetida à secagem em estufa a $60{ }^{\circ} \mathrm{C}$ com ventilação de ar durante 36 horas até atingir umidade entre 11 e $12 \%$, sendo posteriormente prensada em prensa mecânica, sob a força de $9 \mathrm{t}$, em temperatura ambiente. O óleo obtido, escoado pelo dispositivo coletor da prensa, foi recolhido em béquer e imediatamente acondicionado em embalagens de vidro âmbar, e encaminhado às análises físico-químicas. A secagem da polpa foi acompanhada a cada 2 horas por intermédio de amostra representativa, sendo observada a perda de massa em relação à amostra in natura.

\subsection{PREPARO DA FARINHA DA POLPA DE ABACATE}

O resíduo da polpa de abacate, após a extração do óleo, foi triturado em moinho de facas, obtendo-se farinha com granulometria de 65 mesh.

A farinha foi acondicionada em embalagens de polietileno de alta densidade e submetida às análises físico-químicas.

\subsection{ELABORAÇÃO DOS BISCOITOS}

Para a produção dos biscoitos foram avaliados os efeitos das seguintes variáveis na substituição parcial da farinha de trigo e da manteiga: quantidade de farinha e óleo da polpa de abacate, que variaram entre 10 e $50 \%(\mathrm{~m} / \mathrm{m})$ e entre 2,5 e $7,5 \%(\mathrm{~m} / \mathrm{m})$, respectivamente. A escolha desses percentuais de farinha e óleo baseou-se em pré-testes, estando indicadas na Tabela 2 as informações referentes às formulações de biscoito integral desenvolvidas.

\section{TABELA 2 - PLANEJAMENTO FATORIAL DOS BISCOITOS COM FARINHA E ÓLEO DE ABACATE}

\begin{tabular}{ccc}
\hline \multirow{2}{*}{ Tratamento } & Farinha de Abacate $(\% \mathrm{~m} / \mathrm{m})$ & Óleo de abacate $(\% \mathrm{~m} / \mathrm{m})$ \\
\hline 1 & 10 & 2,5 \\
2 & 50 & 2,5 \\
3 & 10 & 7,5 \\
4 & 50 & 7,5 \\
5 & -- & --- \\
\hline
\end{tabular}

$\mathrm{T}_{1}=10 \%$ Farinha da polpa e 2,5 \% Óleo de abacate; $\mathrm{T}_{2}=50 \%$ Farinha da polpa e 2,5 \% Óleo de abacate; $\mathrm{T}_{3}=10 \%$ Farinha da polpa e 7,5 \% Óleo de abacate; $\mathrm{T}_{4}=50 \%$ Farinha da polpa e 7,5 \% Óleo de abacate; $\mathrm{T}_{5}=$ Tratamento Padrão.

Os biscoitos foram elaborados realizando-se a mistura dos ingredientes, o amassamento, a moldagem, o cozimento da massa $\left(185^{\circ} \mathrm{C} / 7\right.$ minutos $)$ e o resfriamento, seguido pelo acondicionamento e a armazenagem. 


\subsection{ANÁLISES}

\subsubsection{Análises Físico-Químicas}

As avaliações físico-químicas foram realizadas conforme o Instituto Adolfo Lutz (1985) e os carboidratos determinados de acordo com a RDC 360 da ANVISA (BRASIL, 2003), sendo expressas as médias das triplicatas.

Para a avaliação da farinha da polpa de abacate e das formulações de biscoito executaramse as análises de acidez total titulável, umidade, cinzas, proteínas, lipídios, fibras e carboidratos. $\mathrm{Na}$ polpa in natura foram efetuadas as análises mencionadas, com exceção de fibras e carboidratos, além das análises de sólidos solúveis totais ( ${ }^{\circ}$ Brix), pH e relação acidez total titulável e sólidos solúveis totais (ATT/SST). Realizou-se também a análise de atividade de água, considerando a faixa de temperatura entre $15-25^{\circ} \mathrm{C}$. Determinou-se no óleo de abacate o índice de acidez, o índice de saponificação e o índice de peróxidos.

\subsubsection{Análise Sensorial dos Biscoitos Integrais}

As formulações foram avaliadas no mesmo dia da elaboração dos biscoitos. A disposição das amostras seguiu delineamento em blocos incompletos ao acaso $(t=5, k=2, r=4)$, de acordo com Hinkelmann e Kempthorne (1994), utilizando-se 30 julgadores não treinados.

Cada julgador recebeu um biscoito de cada tratamento em prato descartável, codificado com números de 3 dígitos de forma aleatória. Os consumidores utilizaram água destilada, à temperatura ambiente $\left(20 \pm 2{ }^{\circ} \mathrm{C}\right)$ entre as amostras para limpeza do palato. Avaliaram-se os atributos sabor, cor, textura, aroma e impressão global, utilizando escala hedônica de 9 pontos, tendo por extremos as expressões "desgostei muitíssimo" (1) e "gostei mutíssimo" (9).

Determinou-se $o$ índice de aceitabilidade (IA), mediante a expressão: IA (\%) = A x 100/B, em que $\mathrm{A}=$ nota média obtida para o produto, e $\mathrm{B}=$ nota máxima dada ao produto. $\mathrm{O} \mathrm{I} \mathrm{A}$ com boa repercussão têm sido considerado $\geq 70 \%$ (MONTEIRO, 1984).

\subsubsection{Análise Estatística}

Os resultados do Planejamento Experimental foram submetidos à análise de efeitos empregando-se o software STATISTICA 7.0 (STATSOFT, 2004). Nos dados da avaliação sensorial aplicou-se análise de variância (ANOVA) e teste de Tukey, ao nível de $5 \%$ de probabilidade, utilizando o mesmo programa estatístico.

\section{RESULTADOS E DISCUSSÂO}

\subsection{PESO PERCENTUAL DO ABACATE IN NATURA}

Os frutos da variedade Margarida apresentaram peso médio de $735 \mathrm{~g}$, mostrando expressivo rendimento em polpa $(78,11 \%)$. O caroço representou $12,49 \%$ do fruto e a casca $9,40 \%$. Os valores obtidos para a polpa do abacate Margarida superaram os dados divulgados por Salgado et al. (2008) e Barbosa et al. (2010) que observaram valores de $66,0 \%$ e 70,8 \%, respectivamente, para polpa de abacate da mesma variedade.

\subsection{ANÁLISES FÍSICO-QUÍMICAS DA POLPA, FARINHA E ÓLEO DE ABACATE}

A legislação brasileira não apresenta limites mínimos e máximos para a composição da polpa de abacate, sendo utilizados dados comparativos da literatura para a discussão dos resultados obtidos. A composição da polpa de abacate in natura consta da Tabela 3.

O teor de sólidos solúveis representa bom indicativo do ponto de maturação de frutos, 
sendo que valor superior a 7,0 (encontrado neste trabalho) pode ser considerado adequado para realização da secagem da polpa (DOS SANTOS et al., 2012).

\section{TABELA 3 - COMPOSIÇÃO DA POLPA DE ABACATE IN NATURA DA VARIEDADE MARGARIDA}

\begin{tabular}{ccc}
\hline Análise & Dados Obtidos & Literatura* $^{*}$ \\
\hline Sólidos Solúveis Totais ('Brix) & 7,33 & --- \\
pH & 7,52 & -- \\
Acidez Total Titulável (\%) & 0,93 & -- \\
ATT/SST & 0,13 & -- \\
Umidade (\%) & 84,15 & 83,80 \\
Cinzas (\%) & 0,90 & 0,50 \\
Lipídios (\%) & 7,59 & 8,4 \\
Proteínas (\%) & 1,71 & 1,2 \\
Atividade Água (Aw) & 0,9984 & --- \\
\hline
\end{tabular}

*Tabela de Composição de Alimentos -TACO (UNICAMP, 2006)

Valor de $\mathrm{pH}$ próximo a neutralidade $(7,52)$ e a baixa acidez do fruto $(0,93 \%)$ demonstram que o abacate pode ser consumido, tanto em preparações doces como salgadas (KOLLER, 1992). A relação ATT/SST $(0,13)$ também corrobora essa afirmação.

O valor encontrado para umidade do abacate ficou próximo ao descrito pela TACO (UNICAMP, 2006), mostrou-se pouco superior ao obtido por Moreno et al. (2003) (77,3\%) e bastante superior ao mencionado por Salgado et al. (2008) para a mesma variedade $(58,35)$.

A atividade água da polpa de abacate in natura foi verificada em três (3) diferentes porções da amostra, ou seja, próximo ao caroço, entre o caroço e a casca e próximo a casca. A média das determinações $(0,9984)$ indicou que a água livre representa grande parte do conteúdo de umidade, o que torna a polpa in natura altamente susceptível a sofrer alterações microbiológicas.

Os resultados de cinzas e proteínas do abacate foram superiores aos descritos pela TACO (UNICAMP, 2006), sendo ambos os componentes encontrados em maiores teores por Moreno et al. (2003) (1,6 \% para proteína e 1,3\% para cinzas). Também o valor proteico descrito por Salgado et al. (2008) para abacates Margarida foi superior (2,54\%). Contudo, Francisco e Baptistella (2005) relataram que abacates apresentam valores de 1 a $3 \%$ de proteína dependendo da variedade.

O valor observado para lipídios manteve-se próximo ao descrito pela TACO (UNICAMP, 2006), mas inferior aos encontrados por Salgado et al. (2008), Crizel et al. (2008) e Moreno et al. (2003) que relatam quantidades de $26,31 \%, 29,00 \%$ e $15,80 \%$, respectivamente, em polpa de abacate da variedade Margarida. Essas diferenças, provavelmente, são devidas às variações nos teores de umidade da polpa in natura.

A farinha de abacate mostrou alto conteúdo de fibras (24,99\%), superior ao de farinhas elaboradas com resíduos de acerola e umbu (ABUD e NARAIN, 2009). Esse fato é interessante, tendo em vista os benefícios das fibras ao organismo humano. Por outro lado, o teor de carboidratos relativamente baixo (16,49 \%) não influencia de forma expressiva o valor calórico da farinha.

A farinha obtida da polpa de abacate (Tabela 4 ) revelou alto valor de acidez $(3,54 \%)$, que pode estar relacionado com o alto teor de lipídios ainda presente na farinha $(37,50 \%)$. Durante a extração do óleo realizou-se somente a prensagem mecânica da polpa desidratada, sem a lavagem com solvente para retirada dos lipídios residuais, o que permite maior teor de lipídios na farinha (DOS SANTOS et al., 2012). Além disso, a redução no teor de umidade da farinha promoveu a concentração desse componente. Para Marini, Gutkoski e Elias (2007), outro fator importante para manter o índice de acidez em níveis aceitáveis envolve a inativação de enzimas como as lipases, as quais produzem ácidos graxos livres que podem contribuir para a elevação da acidez. Os mesmos 
autores citam que a redução na atividade lipolítica inicia-se a $60^{\circ} \mathrm{C}$, entretanto temperaturas mais elevadas $\left(105^{\circ} \mathrm{C}\right)$ apresentam maior efeito sobre lipases. Assim, considerando as condições de secagem utilizadas neste estudo pode ter ocorrido apenas inativação parcial dessas enzimas, tendo em vista os valores elevados de acidez observados.

\section{TABELA 4 - COMPOSIÇÃO DA FARINHA DA POLPA DE ABACATE DA VARIEDADE MARGARIDA}

\begin{tabular}{ccccc}
\hline Determinações & Dados Obtidos & $\begin{array}{c}\text { Farinha de Trigo } \\
\text { Tipo 1* }\end{array}$ & $\begin{array}{c}\text { Farinha de Trigo } \\
\text { Integral* }\end{array}$ & Farinha de Trigo** \\
\hline $\begin{array}{c}\text { Acidez Total } \\
\text { Titulável (\%) }\end{array}$ & 3,54 & -- & --- & --- \\
Umidade (\%) & 11,52 & Máx.15,0 & Máx.15,0 & 13 \\
Cinzas (\%) & 0,90 & Máx. 0,8 & Máx.2,5 & 0,8 \\
Lipídios (\%) & 37,50 & --- & --- & 1,4 \\
Proteínas (\%) & 8,6 & Mín.7,5 & Mín.8,0 & 9,8 \\
Fibras (\%) & 24,99 & --- & --- & --- \\
Carboidratos (\%) & 16,49 & --- & --- & -- \\
Atividade Água (Aw) & 0,4577 & --- & -- & - \\
\hline
\end{tabular}

*Regulamento Técnico de Identidade e Qualidade da Farinha de Trigo (BRASIL, 2005).

* *Tabela de Composição de Alimentos - TACO (UNICAMP, 2006)

Quanto ao percentual de cinzas da farinha, os dados aproximaram-se ao estabelecido para farinha de trigo, enquanto para a umidade e proteínas os resultados enquadraram-se nos valores preconizados pela legislação vigente para farinhas de trigo (BRASIL, 2005).

A redução da umidade da polpa para a extração do óleo resultou em expressivo decréscimo da atividade de água da farinha da polpa, pois boa parte da água livre e da água combinada foram eliminadas durante a secagem.

A acidez do óleo $\left(3,26 \mathrm{mg} \mathrm{KOH} . \mathrm{g}^{-1}\right)$, obtido por prensagem a frio da polpa desidratada, estava de acordo com o valor indicado pela legislação (BRASIL, 2005) para óleos prensados a

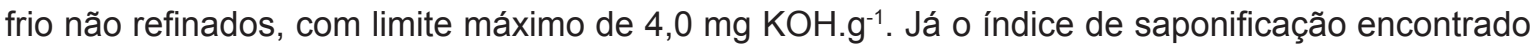
$\left(187,86 \mathrm{mg} \mathrm{KOH} . \mathrm{g}^{-1}\right)$ aproximou-se muito do resultado determinado por Salgado et al. (2008), ou seja, $184,10 \mathrm{mg} \mathrm{KOH} . \mathrm{g}^{-1}$. A presença de peróxidos não foi detectada na amostra de óleo analisada, podendo-se considerar que o teor desses compostos estava abaixo do limite de detecção do método utilizado (titulométrico).

\subsection{ANÁLISES FÍSICO-QUÍMICAS DAS FORMULAÇÕES DE BISCOITO INTEGRAL}

A acidez total titulável das formulações de biscoito integral foi significativamente maior para aquelas contendo farinha de abacate (Tabela 5). Considerando a elevada acidez da farinha de abacate $(3,54 \%)$, sua adição na formulação do biscoito influenciou o aumento desse parâmetro. Entre as diferentes formulações contendo farinha e óleo de abacate, os resultados de acidez não mostraram diferença estatisticamente significativa. Todas as formulações apresentaram dados acima do estipulado pela legislação, inclusive a padrão, o que evidencia que a farinha e o óleo de abacate não foram os únicos responsáveis pela elevada acidez do produto. Assim, deve-se considerar a possível influência da adição de raspas de laranja nas formulações desenvolvidas. 


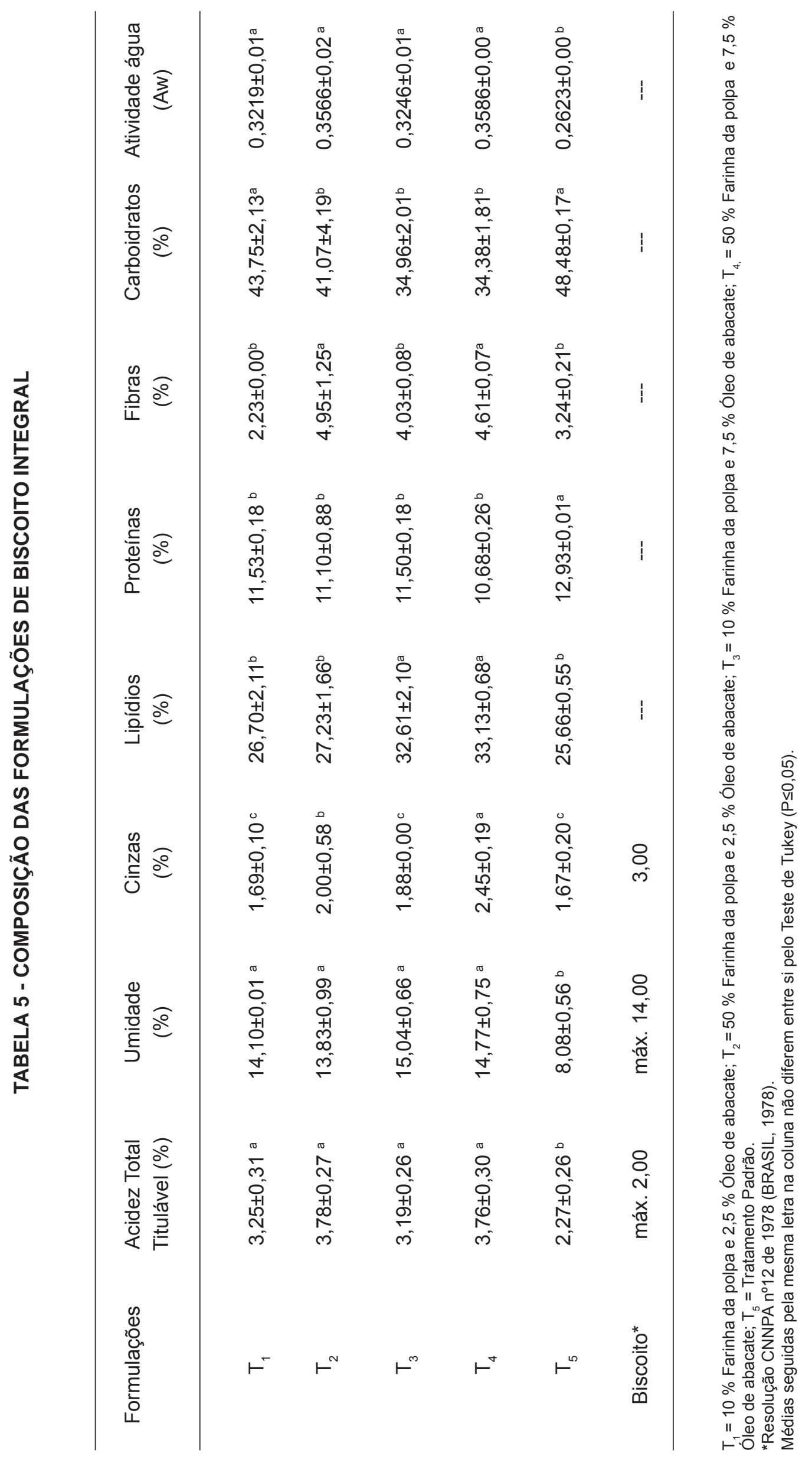


Com relação à umidade, a formulação padrão apresentou valores significativamente inferiores às demais, sendo que apenas essa e a formulação $T_{2}$ ( 50 \% farinha de abacate e 2,5\% de óleo de abacate) se enquadram na faixa preconizada pela legislação. O maior conteúdo de lipídios da farinha de polpa de abacate pode ter promovido certo grau de emulsificação da água, dificultando sua evaporação durante a cocção dos biscoitos. Apesar de estatisticamente as diferenças não serem significativas, as formulações contendo maiores quantidades de óleo de abacate $\left(T_{3}\right.$ e $\left.T_{4}\right)$ apresentaram tendência de elevação de umidade em relação a $T_{2}$ e $T_{1}$, sugerindo que a emulsificação ocorreu em maior grau nas primeiras.

A formulação padrão apresentou o menor valor $(0,2623)$ de atividade água (Tabela 5), já entre as formulações adicionadas de farinha e óleo de abacate as diferenças não foram expressivas. Novamente o possível efeito de emulsificação, em certa medida, reduziu o teor de água livre nos biscoitos.

As formulações com maior proporção de farinha de polpa de abacate $\left(T_{2}\right.$ e $\left.T_{4}\right)$ mostraram valores de cinzas significativamente maiores que as demais, indicando o benefício da adição da farinha de abacate para enriquecer o produto com minerais. Ferro, potássio e zinco são mencionados como importantes minerais encontrados na polpa do abacate (SALGADO et al., 2008).

O percentual de lipídios se elevou com o aumento da proporção de óleo de abacate na formulação do biscoito, sendo que $T_{3}$ e $T_{4}$ (contendo $7,5 \%$ de óleo de abacate) apresentaram valores significativamente maiores que as demais. Por outro lado, não se observou efeito da adição de farinha de abacate em qualquer das proporções utilizadas nesse parâmetro, já que o teor de lipídios de $T_{1}$ e $T_{2}$ não diferiu do obtido para a padrão.

O teor de proteínas diminuiu significativamente com a substituição da farinha de trigo integral pela farinha de polpa de abacate, fato que se explica pela menor concentração de proteínas dessa farinha em relação à de trigo.

As amostras mostraram diferenças significativas quanto às fibras, sendo maior conforme maior a adição da farinha de abacate, fato justificado pela elevado teor de fibras da farinha de abacate.

O teor de carboidratos foi significativamente maior nas formulações padrão e $T_{1}$, com menor grau de adição de farinha e óleo de abacate. Verificou-se pequena redução do percentual de carboidratos nessa formulação, ficando o teor desse componente estatisticamente igual ao da formulação controle $\left(T_{5}\right)$.

\subsection{ANÁLISE SENSORIAL DAS FORMULAÇÕES DE BISCOITO INTEGRAL}

Os resultados obtidos na avaliação sensorial mostraram que a cor dos biscoitos variou significativamente (Tabela 6), principalmente em relação à formulação padrão. Esse fato sugere que a farinha de abacate proporcionou coloração mais escura, influenciando a cor dos biscoitos com maior proporção desse ingrediente. Somente o biscoito com menores teores de farinha e óleo de abacate $\left(T_{1}\right)$ não diferiu da cor da formulação padrão $\left(T_{5}\right)$.

Em relação ao sabor, novamente a formulação $T_{1}$ foi a única que não diferiu da padrão $\left(T_{5}\right)$, sendo essas as melhores classificadas nesse atributo. Verificou-se que maiores teores de farinha e óleo de abacate influenciaram negativamente o sabor dos biscoitos.

Quanto ao aroma, as formulações não diferiram significativamente entre si, demonstrando que a adição da farinha e do óleo de abacate em qualquer das proporções testadas não influenciou a impressão dos consumidores.

No que se refere à textura, foram verificadas algumas diferenças significativas entre as formulações, sendo que a $\mathrm{T}_{4}$ com maiores teores de farinha e óleo de abacate recebeu a menor nota. Uchôa (2007) também relatou diminuição da nota na avaliação sensorial da textura de biscoitos com maior adição de resíduo de caju. 


\section{TABELA 6 - AVALIAÇÃO DOS ATRIBUTOS SENSORIAIS DAS FORMULAÇÕES DE BISCOITO INTEGRAL}

Atributos Sensoriais

\begin{tabular}{cccccc}
\hline Formulações & Cor & Sabor & Aroma & Textura & $\begin{array}{c}\text { Avaliação } \\
\text { Global }\end{array}$ \\
& & & & & \\
\hline$T_{1}$ & $6,83 \pm 1,27^{\mathrm{a}}$ & $7,17 \pm 1,47^{\mathrm{a}}$ & $7,25 \pm 1,14^{\mathrm{a}}$ & $7,33 \pm 1,43^{\mathrm{b}}$ & $7,58 \pm 0,90^{\mathrm{a}}$ \\
$\mathrm{T}_{2}$ & $5,25 \pm 1,14^{\mathrm{b}}$ & $5,50 \pm 1,78^{\mathrm{b}}$ & $7,08 \pm 1,68^{\mathrm{a}}$ & $8,08 \pm 0,90^{\mathrm{a}}$ & $6,33 \pm 1,55^{\mathrm{b}}$ \\
$\mathrm{T}_{3}$ & $5,67 \pm 1,15^{\mathrm{b}}$ & $5,83 \pm 1,34^{\mathrm{b}}$ & $7,08 \pm 1,24^{\mathrm{a}}$ & $7,67 \pm 0,78^{\mathrm{a}}$ & $7,08 \pm 0,90^{\mathrm{a}}$ \\
$\mathrm{T}_{4}$ & $4,50 \pm 1,31^{\mathrm{b}}$ & $4,75 \pm 1,9^{\mathrm{b}}$ & $5,92 \pm 2,27^{\mathrm{a}}$ & $6,17 \pm 1,70^{\mathrm{c}}$ & $5,17 \pm 1,80^{\mathrm{c}}$ \\
$\mathrm{T}_{5}$ & $8,25 \pm 0,87^{\mathrm{a}}$ & $7,83 \pm 1,19^{\mathrm{a}}$ & $7,08 \pm 1,51^{\mathrm{a}}$ & $7,92 \pm 0,79^{\mathrm{a}}$ & $7,75 \pm 1,05^{\mathrm{a}}$ \\
\hline
\end{tabular}

$\mathrm{T}_{1}=10 \%$ Farinha da polpa e $2,5 \%$ Óleo de abacate; $\mathrm{T}_{2}=50 \%$ Farinha da polpa e 2,5 \% Óleo de abacate; $\mathrm{T}_{3}=10 \%$ Farinha da polpa e 7,5 \% Óleo de abacate; $T_{4}=50 \%$ Farinha da polpa e 7,5 \% Óleo de abacate; $T_{5}=$ Tratamento Padrão.

Médias seguidas pela mesma letra na coluna não diferem entre si pelo Teste de Tukey $(P \leq 0,05)$.

$\mathrm{Na}$ avaliação global, as formulações padrão e com menores conteúdos de farinha e óleo de abacate $\left(\mathrm{T}_{5}\right.$ e $\left.\mathrm{T}_{1}\right)$ obtiveram maiores notas, revelando elevado índice de aceitabilidade $\left(86,30 \%\right.$ e $80,37 \%$ respectivamente). Somente a amostra $\mathrm{T}_{4}$ (biscoito contendo $50 \%$ farinha de polpa de abacate e 7,5\% óleo de abacate) mostrou índice de aceitabilidade inferior a $70 \%$ (68,49 \%), indicando menores possibilidades de aceitação no mercado (MONTEIRO, 1984).

As amostras padrão, $T_{1}, T_{2}$ e $T_{3}$ enquadraram-se entre as descrições sensoriais "gostei ligeiramente" a "gostei muito", enquanto que $\mathrm{O}_{4}$ classificou-se entre "indiferente" e "gostei ligeiramente".

O uso de processo de extração do óleo da polpa mais eficiente e a neutralização do óleo obtido podem favorecer as características sensoriais dos produtos elaborados com essas matériasprimas. Essa hipótese está sendo testada em novos trabalhos deste grupo de pesquisa.

\section{CONCLUSÃO}

Os abacates da variedade Margarida apresentam tamanho grande, com bom rendimento em polpa (aproximadamente $78 \%$ em relação a massa total do fruto). As características físicoquímicas da polpa enquadraram-se nas faixas divulgadas na literatura. Já a farinha obtida apresentou elevado teor de lipídios em função do processo de extração por prensagem mostrar baixa eficiência, resultando em elevada acidez da farinha. Por outro lado, pode ser considerado como positivo o expressivo teor de fibras encontrado, dada a funcionalidade desse componente. Quanto aos demais parâmetros avaliados, a farinha de abacate mostrou-se similar às farinhas de trigo convencional e integral.

O óleo da polpa de abacate apresentou características adequadas quanto aos quesitos avaliados.

As características físico-químicas dos biscoitos elaborados com farinha e óleo de abacate foram afetadas pelo expressivo teor de lipídios da farinha e sua elevada acidez. O uso de processo de extração do óleo mais eficiente e sua neutralização poderiam beneficiar os produtos. Contudo, a elaboração dos biscoitos com o resíduo da polpa oriunda da extração do óleo mostrou-se viável, já que três das quatro formulações testadas foram bem aceitas sensorialmente.

As características sensoriais do produto foram favorecidas pelo menor grau de substituição 
da farinha integral e manteiga por farinha de polpa de abacate e óleo de abacate.

Os resultados produzidos indicam novas possibilidades de utilização do abacate e devem servir de base para novas pesquisas que resultem em produtos sensorialmente aceitos e com potencias efeitos benéficos à saúde dos consumidores.

\section{ABSTRACT}

\section{PREPARATION OF WHOLE COOKIE USING AVOCADO PULP FLOUR AND OIL}

The objective of this work was to prepare biscuits using whole flour and oil of avocado pulp and evaluate their physicochemical and sensory characteristics. Thus the pulp of the avocado (Margarida variety) was dehydrated, cold pressed to extract the oil and ground for flour production. In five of the cookies formulations prepared, exception made to control standard formulation, butter and whole wheat flour were partially substituted by avocado pulp and avocado oil in different proportions. The pulp of avocado (Margarida variety) in general, presented similar characteristics to those described in the literature, while the flour obtained from the pulp presented similarity to the characteristics of conventional and whole wheat flour. Cookies prepared with flour and avocado oil showed higher levels of acidity and moisture that the standard formulation, while the formulations containing higher amounts of avocado flour had higher concentration of minerals and fibers. The sensory evaluation revealed good acceptance of cookies, however the formulations with lower proportions of avocado flour and oil presented the best sensory characteristics.

KEY-WORDS: WHOLE COOKIES; AVOCADO; AVOCADO OIL; AVOCADO PULP FLOUR.

\section{REFERÊNCIAS}

1 ABUD, A.K.S. de; NARAIN, N. Incorporação da farinha de resíduo do processamento de polpa de fruta em biscoitos: uma alternativa de combate ao desperdício. Brazilian Journal Food Technology, v. 12, n. 4, p. 257-265, out./dez. 2009.

2 BARBOSA, P.P.M. de.; PRATES, F.C.; OLIVEIRA, M.C. de.; SILVA, A.C.F.C.E.; LIMA, L.C.O. de.; RAMOS, J. D. Avaliação física de cultivares de abacate visando a produção de biodiesel e óleo comestível. In: CONGRESSO DE PÓSGRADUAÇÃO DA UFLA, 19., 2010, Lavras. Anais... Lavras: UFLA, 2010.

3 BERASATEGI, I.; BARRIUSO, B.; ANSORENA, D.; ASTIASARÁN, I. Stability of avocado oil during heating: comparative study to olive oil. Food Chemistry, v. 132, p. 439-446, 2012.

4 BORGES, M.H.C.; MELO, B. A cultura do abacateiro. Disponível em: http://www.fruticultura.iciag.ufu.br/abacate. html\#3aspectosbotânicos. Acesso em: 01/06/2011.

5 BRASIL. Agência Nacional de Vigilância Sanitária. Resolução CNNPA nº12 de 1978. Aprova as normas técnicas especiais. Diário Oficial [da] República Federativa do Brasil, Brasília, DF, 24 de julho de 1978. Seção 1, pt. I.

6 BRASIL. Agência Nacional de Vigilância Sanitária. Resolução RDC no 360 de 2003. Aprova o regulamento técnico sobre rotulagem nutricional de alimentos embalados. Diário Oficial [da] República Federativa do Brasil, Brasília, DF, 26 de dezembro de 2003. Seção 1, p. 33.

7 BRASIL. Agência Nacional de Vigilância Sanitária. Resolução RDC nº 270, de 22 de setembro de 2005. Aprova regulamento técnico para óleos vegetais, gorduras vegetais e cremes vegetais. Diário Oficial [da] República Federativa do Brasil, Brasília, DF, 23 de setembro de 2005. Seção 1, p. 372.

8 BRASIL. Ministério de Agricultura, Pecuária e Abastecimento. Instrução normativa n 8, 03 junho de 2005. Regulamento técnico de identidade e qualidade da farinha de trigo. Diário Oficial [da] República Federativa do Brasil, Brasília, DF, 03 de junho de 2005, Seção 1, p. 91.

9 CANCIAM, C.A.; SANTOS, J.T. dos.; OLEGARIO, T.G. Elaboração e análise de iogurte sabor abacate. In: SEMANA DE TECNOLOGIA EM ALIMENTOS - UTFPR, 4., 2008, Ponta Grossa. Anais... Ponta Grossa: UTFPR, 2008.

10 CRIZEL, G.R.; MOURA, R.S.; MENDONÇA, C.R.B.; RAMIS-RAMOS, G. Caracterização de abacates visando o seu potencial para a extração de óleo conforme a variedade. In: SIMPÓSIO DE SEGURANÇA ALIMENTAR - DEBATENDO QUALIDADE, 2., 2008, Bento Gonçalves. Anais... Bento Gonçalves: SBCTA-RS, 2008.

11 DAIUTO, E.R.; VIEITES, R. L.; TREMOCOLDI, M.A.; VILEIGAS, D.F. Estabilidade físico-química de um produto de abacate acondicionado em diferentes embalagens e conservado pelo frio. Alimentos e Nutrição, Araraquara v. 21, n.1, p. 99-107, jan./mar. 2010.

12 DING, H.; CHIN, Y.W.; KINGHORN A.D.; D'AMBROSIO, S.M.D. Chemopreventive characteristics of avocado fruit. Seminars in Cancer Biology, v. 17, p. 386-394, 2007 
13 DOS SANTOS, M.A.Z; ALICIEO, T.V.R.; PEREIRA, C.M.P.; RAMIS-RAMOS, G.; MENDONÇA, C.R.B. Profile of bioactive compounds in avocado pulp oil: influence of dehydration temperature and extraction method. Journal of the American Oil Chemists' Society, 2012. in press.

14 FRANCISCO, V.L.F.S. dos.; BAPTISTELLA, C.S.L. da. Cultura do abacate no Estado de São Paulo. Revista Informações Econômicas, v. 35, n. 5, p.27-41, maio. 2005.

15 HINKELMANN, K.; KEMPTHORNE, O. Design and analysis of experiments. New York: Wiley, 1994. p. 290-296.

16 INSTITUTO ADOLFO LUTZ. Normas analíticas do Instituto Adolfo Lutz: métodos químicos e físicos para análises de alimentos. 3. ed. São Paulo: Impressa Oficial do Estado de São Paulo, 1985. v. 1.

17 KOLLER, O. C. Abacaticultura. Porto Alegre: UFRGS, 1992.138 p.

18 MONTEIRO, C. L. B. Técnicas de avaliação sensorial. 2.ed. Curitiba: CEPPA-UFPR, 1984. 101 p.

19 MARINI, L.J.; GUTKOSKI, L.C.; ELIAS, M.C. Efeito da temperatura de secagem e relação de intermitência na inativação enzimática e viscosidade de pasta de aveia. Revista Brasileira de Agrociencia, v.13, n. 1, p. 55-60, 2007.

20 MORENO, A.O.; DORANTES. L.; GALÍNDEZ, J.; GUZMÁN, R.I. Effect of different extraction methods on fatty acids, volatile compounds, and physical and chemical properties of avocado (Persea americana Mill) oil. Journal of Agricultural and Food Chemistry, v. 51, p. 2216-2221, 2003.

21 MOSTERT, M.E.; BOTHA, B.M.; PLESSIS, L.M.D.; DUODU, K.G. Effect of fruit ripeness and method of fruit drying on the extractability of avocado oil with hexane and supercritical carbon dioxide. Journal of the Science of Food and Agriculture, v. 87, p. 2880-2885, 2007.

22 OLIVEIRA, M.C.; PIO, R.; RAMOS, J.D.; LIMA, L.C.O.; PASQUAL, M.; SANTOS, V.A. Fenologia e características físicoquímicos de frutos de abacateiro visando a extração de óleo. Ciência Rural, v.43, n.3, p.411-418, 2013.

23 OZDEMIR, F.; TOPUZ, A. Changes in dry matter, oil content and fatty acids composition of avocado during harvesting time and post-harvesting ripening period. Food Chemistry, v. 86, p. 79-83, 2004.

24 STATSOFT, INC. Statistica for Windows: computer program manual. Tulsa, OK, USA, 2004.

25 ROCHA, T.E.S. da. Composição de ácidos graxos e de fitoesteróis em frutos de quatro variedades de abacate (Persea Americana Mill). 2008. 85 p. Dissertação (Mestrado em Nutrição Humana), Faculdade de Ciências da Saúde, Universidade de Brasília, Brasília, 2008.

26 SALGADO, J.M.; DANIELI, F.; REGINATO-DARC'E, M.A.B.; FRIAS, A.; MANSI, D.M. O óleo de abacate (Persea americana Mill) como matéria-prima para indústria alimentícia. Ciência e Tecnologia de Alimentos, Campinas, v. 28, p. 20-26, dez. 2008

27 TANGO, J.S.; CARVALHO, C.R.L.; SOARES, N.B. Caracterização física e química de frutos de abacate visando a seu potencial para extração de óleo. Revista Brasileira de Fruticultura, Jaboticabal, v.26, n.1, p.17-23, abr. 2004.

28 UCHÔA, A.M.A. Adição de pós alimentícios obtidos de resíduos de frutas tropicais na formulação de biscoito. 2007. 89 p. Dissertação (Mestrado em Tecnologia de Alimentos), Departamento de Tecnologia Alimentos, Centro de Ciências Agrárias, Universidade Federal do Ceará, Fortaleza, 2007.

29 Universidade de Campinas (UNICAMP). Tabela brasileira de composição de alimentos (TACO). 2. ed. Campinas, 2006 